\title{
Redes colaborativas entre colectivos culturales y redefinición de la comunidad: el caso de la lucha por la derogación del Código de Faltas en Córdoba, Argentina.
}

\author{
Laura Maccioni \\ Universidad Nacional de Córdoba- CONICET- Argentina \\ Gabriel Loyber \\ Universidad Nacional de Córdoba- Argentina
}

\begin{abstract}
Resumo
O artigo examina as práticas colaborativas de um conjunto de coletivos da cidade de Córdoba, Argentina, que, por meio de sua produção em rede, procuram desconstruir a matriz cultural de preconceitos que recolhe $\mathrm{e}$ legaliza o assim chamado "Código de Faltas". Este Código é uma lei provincial que qualifica, arbitrariamente, como "faltas" certas condutas -tais como a "vagueação"-, que penaliza por afetar supostamente a convivência social, constituindo na prática um instrumento para a perseguição e a detenção de jovens, pobres e de tez escura. Os coletivos que estudamos aqui levam a cabo uma série de operaçôes de ressignificação dos modos em que se entendem o espaço, o tempo e a participação na produção, performando outras formas de sociabilidade mais igualitárias e habilitando a emergência de novos sujeitos antes já invisibilizados.
\end{abstract}

Palavras-chave: coletivos culturais; práticas colaborativas; Código de Faltas.

\section{Resumen}

El artículo examina las prácticas colaborativas de un conjunto de colectivos de la ciudad de Córdoba, Argentina, que, a través de su producción en red, procuran deconstruir la matriz cultural de prejuicios que recoge y legaliza el llamado "Código de Faltas". Este Código es una ley provincial que califica arbitrariamente como "faltas" ciertas conductas -tales como el "merodeo"-, que penaliza por afectar, supuestamente, la convivencia social, constituyendo en la práctica un instrumento para la persecución y detención de jóvenes, pobres y de tez oscura. Los colectivos que aquí estudiamos llevan a cabo una serie de operaciones de resignificación de los modos en que se entienden el espacio, el tiempo y la participación en la producción, performando otras formas de sociabilidad más igualitarias y habilitando la emergencia de nuevos sujetos invisibilizados desde antes.

Palabras clave: colectivos culturales; prácticas colaborativas; Código de Faltas. 
1. ZIMMERMAN, Marc; OCHOA BILBAO, Luis (Coords.). Giros culturales en la marea rosa de América Latina, 2012.

2. RANCIÈRE, Jacques. $E l$ desacuerdo: politica y filosofía, 1996.
En los últimos años, los estudios sobre acción colectiva vienen ocupándose de describir los alcances y las modalidades propios de lo que llaman el "giro cultural" de la política ${ }^{1}$, concediendo particular atención a la dimensión simbólica de formas organizativas novedosas, muchas de las cuales -asambleas barriales, organizaciones de desocupados, fábricas recuperadas, activistas por los derechos a la diferencia sexo-genérica, por los derechos ambientales, entre otros- emergieron en América Latina en el marco del retorno a la democracia. Pese a la multiplicidad de enfoques teóricos y disciplinarios, dichas investigaciones coinciden en afirmar que para comprender estas experiencias en tanto modos de participación política en la esfera pública, es necesario abandonar una definición tradicional de lo político entendido en el sentido estatal/institucional del término, para suscribir, en cambio, a una definición ampliada. Para esa concepción ampliada de la política, que involucra los sentidos que les confieren a sus acciones los sujetos que las llevan a cabo, la participación política va más allá de la respuesta a la convocatoria por parte de un sistema de instituciones, dadas de antemano, que definen quiénes son los convocados y bajo qué condiciones, pues ocurre, fundamentalmente, a través de prácticas que hacen tanto a la definición y construcción de eso común de lo cual se quiere ser parte, como a la identidad de las partes que lo constituyen ${ }^{2}$. Esta idea, como puede inferirse, se opone radicalmente a las versiones metafísicas del sujeto político, puesto que aquí la ciudadanía no tiene que ver con el reconocimiento jurídico de una lista de derechos previamente estipulados hacia los cuales las políticas deberían tender idealmente, sino con el reconocimiento de las exclusiones reales: en tanto los derechos "universales" son expresión de intereses históricos concretos, la exclusión no debe leerse sólo como cumplimiento insuficiente de aquellos sino también como uno de sus efectos. Dicho de otro modo, en su concepción clásica, la noción de ciudadanía se asocia a una lista de derechos "universales" que opera como modelo previo, de manera que el incumplimiento de esos derechos se lee como un déficit, un problema que debe ser tratado a través de intervenciones específicas que permitan alcanzar esos estándares. Por el contrario, lo que han enseñado los movimientos es que la existencia de cifras altísimas de personas que "están de más" no es un error, sino una consecuencia de ese modelo de ciudadanía ideal que no es incompatible con la exclusión real. Ese modelo ideal de ciudadanía por un lado, le confiere a un hombre in abstracto los derechos que en realidad no tiene el hombre concreto, mientras que por otro niega a la condición real de los hombres sin derechos la capacidad de ser el origen de la ley, de crear derechos. La idea de ciudadanía que defienden estos movimientos está, por tanto, íntimamente vinculada a la dinámica de creación de derechos, al derecho a tener derechos entendidos en su indeterminación, y no según una lista ya previamente dada. Se trata, en suma, de un cuestionamiento a la naturalización de los derechos reconoci- 
dos, y una demanda de reconocimiento de nuevos derechos que se van creando según las distintas necesidades.

Al mismo tiempo, esta operación de construcción de nuevas identidades portadoras de nuevos derechos reformula desde su base la noción de comunidad política. Porque para este nuevo modo de entender la ciudadanía lo que se exige no es el acceso, la inclusión y la pertenencia a una determinada sociedad, sino el derecho a participar en la definición del tipo de sociedad del que queremos ser parte, una en la que esté garantizada una socialidad mucho más igualitaria que la actual.

Entonces: todos estos cuestionamientos culturales, disputas y apuestas en el terreno de la significación no son subproductos de la lucha política, medios para un fin superior, sino que son un objetivo en sí mismo. Hay una producción cultural que es transformadora, que desplaza a los sujetos de los lugares de subalternidad que les habían sido asignados por el orden hegemónico, que los de-sujeta, que reconfigura nuevamente su subjetividad y la totalidad del espacio social.

En el caso de Argentina, este "giro cultural" del que hablamos debe situarse además en el marco de un proceso histórico particular. Mientras que en los años inmediatamente posteriores al retorno democrático el principal problema tuvo que ver con el afianzamiento de las formas institucionales, la profunda crisis a la que condujeron las políticas de ajuste de los años ' 90 implicó un cuestionamiento profundo a una concepción de la democracia que, tanto en la teoría como en las prácticas, se había limitado al cumplimiento de procedimientos institucionales que legitiman la elección periódica de un gobierno y al ejercicio de una política de "baja intensidad".

Este proceso histórico alcanzó su punto más dramático en la crisis de 2001, momento en que tienen lugar un sinnúmero de experiencias que buscaron re-pensar creativamente las articulaciones entre Estado y sociedad. Protagonistas principales de este trabajo político-cultural fueron los así llamados colectivos artísticos/ colectivos culturales cuyas experiencias en esos primeros años del siglo veintiuno han sido analizadas por investigadores como Ana Longoni ${ }^{3}$ y Reinaldo Laddaga ${ }^{4}$. Desde entonces, son muchos los autores se han se han detenido a analizar ciertas prácticas colaborativas que reúnen a artistas y no artistas, expertos y no expertos, vecinos, activistas y movimientos sociales en la realización conjunta de proyectos que, a través de intervenciones situadas contextualmente, exploran "la sustancia y la significación de la comunidad [...] qué cosa es la comunidad, qué cosa ha sido, qué cosa podría ser" prácticas artístico/culturales no sea la realización de una "obra" sino la experimentación de modos de organización social que rechazan el tipo de vínculo que configura el imaginario neoliberal. Podría afirmarse, entonces, que es esta red, esta socialidad, lo que se busca como resultado de tales prácticas cooperativas, que
3. LONGONI, Ana,

"Apuntes en medio del campo (de batalla)", 2002, p. 16-21;

"Encrucijadas del arte activista en Argentina”. Ramona, 2007, p. 31-43.

4. LADDAGA, Reinaldo. Estética de la emergencia, 2006; "Mundos comunes. Metamorfosis de las artes del presente". Otra Parte, 2005, p.7-13.

5. LADDAGA, Reinaldo. Estética de la emergencia, 2006, p.9. 
6. EXPOSITO, Marcelo.

"Arte: la imaginación política radical". Instituto europeo para politicas culturales progresivas, 2005, s/p.

7. LECHNER, Norbert. "Los desafíos políticos del cambio cultural". Nueva Sociedad, 2003, p. 46-65.

8. WILLIAMS, Raymond. Cultura: sociología de la comunicación y del arte, 1982. incluyen exposiciones, encuentros, talleres educativos, proyectos de documentación, acciones comunicativas y de difusión o intervenciones en el espacio público; una socialidad, por tanto, que se construye a partir de acciones que desplazan de los lugares previamente asignados a los sujetos en las relaciones de producción, distribución y recepción cultural ${ }^{6}$.

La importancia de un análisis de estas formas de sociabilidad y subjetividad como el que aquí proponemos se percibe con mayor claridad cuando las contraponemos, en el caso particular de Córdoba, con las que ha producido la acción estatal en el campo cultural en los últimos años, en ajustada sintonía con las directrices del mercado. Dicha intervención ha estado orientada fundamentalmente hacia la instrumentalización de los bienes culturales y la fetichización de la figura del artista, la refuncionalización del espacio urbano y de los museos según las necesidades del turismo y la industria del ocio, la espectacularización del arte y su explotación bajo la forma de megafestival/entretenimiento sponsoreado por empresas. Tales intervenciones en el campo de la cultura, que hacen de ésta una mercancía destinada a ser consumida pasivamente por un público, están en correspondencia con un modo de organización de las relaciones sociales y de subjetivación específico que tienen su centro en el individuo como unidad de la vida social y el individualismo como ética predominante, la integración en la vida en común pensada desde el consumo pasivo de bienes, la desmaterialización de las relaciones sociales por la vía de su traducción a cifra estadística con la consecuente disolución de los lenguajes necesarios para la producción colectiva de sentido, la refuncionalización del espacio público según las necesidades del mercado inmobiliario, del negocio turístico o de la administración política de los miedos y la fractura en los procesos de elaboración de un tiempo social que conlleva a que tanto el trabajo de la memoria como la proyección del futuro sean relegados a favor de un tiempo centrado en la vivencia del presente ${ }^{7}$

\section{Re-inventar la comunidad}

En nuestra investigación usamos el término "colectivos culturales" para nombrar actores colectivos plurales cuyas prácticas son culturales no sólo porque utilizan sistemas significantes diversos a nivel "manifiesto" - diría Raymond Williams ${ }^{8}$-, sino porque, en un sentido más amplio, entienden a la cultura como el terreno en el que se juega el modo de vivir juntos. En este marco, estudiamos las prácticas de ciertos colectivos culturales de Córdoba que recurren al lenguaje del teatro, las artes plásticas, el video, la comunicación alternativa, o la producción de información por parte de los vecinos de una biblioteca popu- 
lar, entre otros, asumiendo a manera de hipótesis que ellas no sólo expresan un contenido crítico en torno a nuestras formas actuales de comunidad, sino que, en muchos casos, performan esos otros modos de comunidad posible. $\mathrm{Y}$ es por lo que estas experiencias realizan que estamos interesados en estudiarlas, ya que creemos que ellas pueden aportar a la construcción de una socialidad que no reproduzca nuestros actuales modos de concebir el vínculo comunitario. Se trata, entonces, de identificar formas de contraproductividad ${ }^{9}$

Ahora bien: ¿qué rasgos caracterizan esta socialidad otra que promueven y muchas veces encarnan los colectivos? Desde hace un tiempo tanto la sociología como la antropología urbana y los estudios culturales han mostrado un creciente interés por estas formas asociativas atípicas. En una conferencia en el Centro Cultural Ricardo Rojas de Buenos Aires, Reinaldo Laddaga señala estas "emergencias" y destaca las transformaciones que ellas producen o podrían producir: "Tengo la impresión de que lo que los artistas comienzan crecientemente a hacer es [...] intervenir proponiendo medios para la articulación de conversaciones entre grupos grandes de personas en donde se articule la producción de imágenes o de discursos, y típicamente de imágenes $y$ de discursos, con la intervención y la modificación de estados de cosas locales: la ocupación de un lugar, la realización de un intercambio, la realización de un acto real [...] como la ocupación de un edificio, la realización de un intercambio, la organización de una manifestación. [...] Y, entonces, actos de conversaciones grandes y grupos heterogéneos: que sean más que grupos de amigos, quiero decir, o grupos fundados en una identidad preexistente. Es decir, que sean lugares donde se produzcan conversaciones que puedan ser al mismo tiempo sitios de formación de identidades nuevas y no simplemente reproducción de identidades preexistentes"10 . Estas "ecologias relacionales", tal como las llama el autor, construyen formas experimentales de comunidad que disuelven categorías centrales tanto dentro del campo del arte -autor, obra o autonomía- como de las ciencias sociales - estado, clase, género, familia- disolviendo, a su vez, los límites entre ambas sedes disciplinarias. En cuanto a las características de estos colectivos artísticos y culturales, José Fernández Vega observa ciertos rasgos comunes que éstos suelen compartir: "funcionamiento interno por consensos, régimen de ingreso abierto y rotación de sus integrantes [...], actividad organizada a partir de proyectos particulares [...], acuerdos mínimos, ideal de funcionamiento en red, incluso cooperando con otros grupos. [...] Los grupos se distinguen, es cierto, por sus ocupaciones específicas, sus características, su historia, su localización y sus partes integrantes. Pero sus principios son casi idénticos"11. Scott Lash, por su parte, vincula la declinación de las organizaciones del capitalismo moderno con la aparición de lo que llama desorganizaciones, entendidas no como ausencia de organización, sino como
9. FOUCAULT, Michel. "Las redes del poder", 1991, p. 49-72.

10. LADDAGA, Reinaldo. "La producción de algo así como de vida social artificial: la práctica artística en una nueva cultura global". Ramona, 2004, p. 14

11. FERNÁNDEZ VEGA, J.

"Más y más variedades de lo mismo y de lo otro". Ramona, 2003, p.84. 
12. LASH, Scott. Crítica de la información, 2005, p. 73-77.

13. LEFEBVRE, Henry. Espacio y politica. El derecho a la ciudad II, 1976. nuevas formas de sociación. Según Lash ${ }^{12}$, éstas se caracterizan por ser menos jerárquicas que horizontales y están coordinadas no de manera normativa sino en función de valores. Sin embargo, esa adscripción a valores no es la de las formas asociativas clásicas en las que los valores, por ejemplo la virtud, constituían una axiología fija. Por el contrario, las desorganizaciones actuales no reproducen valores sino que innovan y los producen constantemente, de manera fluida y sometida a permanente autorreflexión. Mientras las asociaciones se basan en los individuos abstractos y las reglas que impone la membrecía, las sociaciones -sostiene Lash-se basan en el reconocimiento mutuo y la pertenencia afectiva basada en la coproducción de horizontes. Las sociaciones desbaratan, así, los límites de lo privado y lo público.

Sin embargo, si bien existe una abundante producción teórica que da cuenta de las nuevas rearticulaciones de lo social y lo cultural en estas formas de socialidad alternativas, creemos necesario avanzar en la producción de indicadores específicos que nos permitan leer lo nuevo de estas nuevas emergencias. ¿Dónde mirar para dar cuenta de estas innovaciones? ¿En qué dimensiones de las prácticas? Nuestro relevamiento preliminar de colectivos culturales en la ciudad de Córdoba, Argentina, nos ha llevado a recortar provisoriamente tres zonas en las que, con frecuencia, suelen registrarse las marcas de este trabajo de reinvención micropolítica del modo de vivir juntos.

La primera tiene que ver con el espacio, al que entendemos no sólo como un dato físico que constituye el soporte natural de prácticas sociales. Por el contrario, nos interesa registrar las tensiones entre aquello que Henri Lefebvre llamó representaciones del espacio, y lo que denominó espacios de la representación ${ }^{13}$. En el primer caso, se trata de una representación del espacio a través de los códigos propios de urbanistas, geógrafos, planificadores y técnicos que da por resultado cartografías y geopolíticas. Por el contrario, los espacios de la representación emergen como resultado de la producción simbólica de sus habitantes, quienes, en el marco de su experiencia cotidiana, generan otras territorialidades posibles que exceden/subvierten los límites jurídicos y administrativos. Estos espacios creados por la imaginación colectiva constituyen un recurso fundamental en las luchas por el reconocimiento de la primacía del valor de uso de la ciudad por sobre su mero valor de cambio calculado en base a la propiedad privada del suelo y las oportunidades de desarrollo inmobiliario. Y también es un recurso con valor político, en tanto el espacio es constitutivo de las experiencias que estamos estudiando, y no su mero soporte o escenario: esto es, transformar el espacio es también transformar la subjetividad y la socialidad de quienes lo habitan, pero lo inverso también es cierto. Las transformaciones en la subjetividad que redefinen que es lo exhibible y qué es ocultable, qué es tolerable y qué condenable en el espacio público, qué actividades sociales están permitidas y cuáles no, etc. tienen efectos de redefinición del espacio y de sus usos. 
Estrechamente ligado a las redefiniciones del espacio, encontramos la dimensión de la temporalidad. En este punto hemos podido registrar transformaciones que muchos de estos colectivos producen en la concepción del tiempo como ritmo cotidiano y como memoria. En el primer caso, nos interesa ver qué alternativas se ofrecen a un tiempo cotidiano regulado por las exigencias del sistema productivo y por tanto organizado estrictamente en tiempo de trabajo/tiempo de ocio. En nuestra investigación nos detenemos fundamentalmente a analizar la idea de ocio, y buscamos ver de qué modo los colectivos aportan a la doble deconstrucción de una idea de ocio asociada exclusivamente a la posibilidad del consumo privado de bienes y servicios de entretenimiento, y, por otro lado, a la idea del ocio asociada al vicio, riesgo o "tiempo perdido". Por el contrario, las experiencias que estamos estudiando muestran que muchas de las actividades desarrolladas en el marco de estos colectivos (murgas, circos, talleres de poesía, pintura de murales callejeros, etc.) se plantean como resistencia a los dispositivos de socialización programada para el tiempo libre y entienden a este tiempo no como actividad no productiva, sino como momento destinado a la efectuación de lo que Foucault llamó prácticas de sí : prácticas que, socavando los sistemas semióticos dominantes que fijan nuestra subjetividad según modelos dados de antemano, apuntan a lograr una cierta soberanía sobre sí mismo al habilitar la posibilidad de una reflexión crítica en torno a cómo hemos llegado a ser lo que somos ${ }^{14}$.

El otro campo de indagación importante en lo referido a la construcción de otras temporalidades por parte de estos colectivos tiene que ver con la memoria, en tanto una parte importante de las narrativas comunitarias que ellos producen implican operaciones de reconfiguración de los pasados y los futuros disponibles en base a un trabajo de crítica y visibilización de lo que aún permanece activo como huella en el presente ${ }^{15}$.

Una última dimensión que estamos explorando es la de las formas de organización de la producción cultural que llevan a cabo estos colectivos. Nos interesa aquí describir los distintos procesos de autogestión que los sostienen, partiendo del supuesto de que su lógica de producción cultural contradice la lógica de la producción de cultura en el neoliberalismo. Mientras que esta última ha privilegiado siempre el valor de cambio por sobre el valor de uso de la cultura, y ha instalado la noción de la participación cultural como acceso desigual a los bienes y servicios producidos en conformidad con las reglas de maximización de ganancias del mercado, los colectivos que estudiamos contraponen una producción y distribución cultural basada en las necesidades de sus miembros y generada a través de procesos que se caracterizan por un alto grado de participación desde el inicio mismo del proceso productivo, no sólo en el momento de la distribución de los productos. Sin embargo, consideramos que la
14. Michel Foucault sostiene que "por lo general, se puede decir que hay tres tipos de luchas: una contra la forma de dominación (étnica, social y religiosa); otra contra las formas de explotación que separan al individuo de lo que produce; $y$ una tercera contra lo que liga al individuo a sí mismo y lo somete a otros en esta forma (lucha contra la sujeción, contra formas de subjetividad y de sumisión).

[...] Y, en nuestros días, las luchas contra las formas de sujeción, contra la sumisión de la subjetividad, se vuelven cada vez más importantes, aun cuando las luchas contra las formas de dominación y explotación no han desaparecido. Todo lo contrario". FOUCAULT, Michel. "Post-scriptum. El sujeto y el poder", 2001, p. 245.

15. JELIN, Elizabeth.

"Exclusión, memorias y luchas políticas", 2005, p. 219-239; JELIN, Elizabeth; LANGLAND, Victoria (comps.). Monumentos, memoriales y marcas territoriales, 2003. 
16. Cf. SANTOS, Boaventura de Sousa. Producir para vivir. Los caminos de la producción no capitalista, 2011. autogestión debe ser entendida como algo más que una serie de técnicas dirigidas a la administración de los recursos económicos destinados a una producción que, para el caso que estudiamos, es cultural: pues precisamente a lo que apunta la noción de autogestión es a cuestionar la operación ideológica del neoliberalismo que consiste en escindir la economía del resto de la vida social presentando esta dimensión como una cuestión neutra y autoevidente, impidiendo así que las decisiones que se tomen en ese campo puedan ser sometidas al cuestionamiento político y a la crítica ${ }^{16}$. La autogestión, por el contrario, trabaja desde la premisa de que la producción económica es indisociable de la reproducción del poder, de la producción de una cultura específica y de la producción de sujetos, e implica una reflexión y una toma de posición política frente a esas cuestiones.

Y aquí corresponde volver de nuevo a lo que decíamos al principio de este trabajo: la producción cultural de estos colectivos tiene que ver no sólo con la cultura en el sentido restringido de la palabra (esto es, como producción manifiestamente significante a través de sistemas semióticos especializados -la pintura, la literatura, el teatro, etc.-) sino con la cultura en el sentido de producción de un modo de vivir juntos, y la producción de los sujetos de esa comunidad. La autogestión podría entonces leerse como uno de esos modos de efectuar, realizar o performar un modo otro de comunidad que opone una alternativa al modo de socialidad que realiza o performa el neoliberalismo como cultura, caracterizado por la privatización de las responsabilidades, la erosión sistemática y deliberada de los vínculos cooperativos a los fines de imponer una socializad basada en la competencia, la traducción de las necesidades sociales a términos exclusivamente monetarios, la presentación de la economía como un sistema autorreferencial e incontrolable, la consecuente pérdida de sentido y de proyecto que permitiría ligarnos a quienes nos precedieron en el pasado y quienes vendrán en el futuro.

Una exploración de estas dimensiones nos ha permitido comenzar a entender qué es lo que se juega en estos colectivos en términos de construcción de subjetividades políticas, así como también qué otras formas de ser/estar con otros pueden imaginarse.

\section{Una producción colectiva para derogar el Código de Faltas}

Pocos casos en la ciudad de Córdoba ilustran de un modo tan claro este trabajo de producción de nuevos significados en torno a la noción de comunidad política y de sujeto político -del 
estar juntos y de ser parte- como las agrupaciones y colectivos que convergen en la lucha por la derogación del llamado Código de Faltas. El Código de Faltas es una ley de la provincia de Córdoba (ley 8431) sancionada en 1994, que pena con multas y/o arrestos ciertas conductas que afectan la convivencia, llamadas contravenciones o "faltas". El código está constituido por una serie de artículos que habilitan un accionar policial arbitrario y violatorio de los derechos garantizados por la constitución nacional, al menos por dos razones. Por un lado, la ambigüedad en la definición de las conductas que prohíbe -tales como "merodeo", "prostitución escandalosa", realización de "reuniones públicas tumultuosas", agravios a la "decencia pública", "escándalo público", entre otras- impide de hecho a los ciudadanos ajustar su comportamiento a lo que la ley exige. Por otro, los criterios para la privación de la libertad quedan a cuenta del aplicador de la norma, es decir, del policía, quien actúa de oficio y sin necesidad de cumplir ningún otro paso procesal, con lo cual los arrestos por "merodeo" -que son los más frecuentes-- han pasado a ser una herramienta sistemática de discriminación y persecución contra sectores que constituyen el blanco de una política de control social que se reduce básicamente a mantener fuera de la ciudad a los varones jóvenes, de tez oscura y pobres.

Pese a que la constitución nacional establece que la libertad ambulatoria sólo puede ser limitada por la actuación de un juez competente, aquí tanto la detención como la sentencia quedan a discreción de la propia policía, sin que medie abogado, juicio ni juez. De más está decir que en una sociedad altamente sensibilizada acerca de la cuestión de la seguridad, el número de detenciones ha pasado a ser el principal indicador a través del cual la policía da muestras de la "eficacia" de sus acciones contra el delito.

Por todo lo señalado anteriormente, se infiere que el debate en torno a la modificación del Código de Faltas va más allá de la sede jurídica, y toca en cambio cuestiones que dejan en evidencia la complejidad del vínculo entre la ley y la cultura: en verdad las enormes resistencias a su derogación ${ }^{17}$ se deben a que el código recoge y legitima prejuicios culturales -racistas, clasistas, morales, etc.- hondamente arraigados en la sociedad, que convalidan ciertas formas de subjetividad y de sociabilidad, habilitando la represión "legal" de otras que son estigmatizadas y criminalizadas.

La posibilidad de lograr la derogación del Código se juega entonces en ese terreno, y es por esto que las organizaciones y colectivos comprometidas en esa lucha enfatizan de manera permanente este aspecto "cultural" de la misma: "mi cara no es tu trabajo" o "mi cara, mi barrio, mi ropa no son delito" son las banderas que levantan quienes participan de esos colectivos y que conducen directamente, nombrándolos en pocas palabras, al núcleo ideológico concreto -joven, moreno, con gorra y ca-
17. A propósito de la convocatoria a la Sexta Marcha de la Gorra, el entonces ministro de seguridad de la Provincia de Córdoba Alejo Paredes declaró a la prensa que "si hubiera marchas a favor del Código de Faltas iría más gente que a las marchas en contra" "'Una masiva marcha de la gorra se realizó por el centro de Córdoba”. La mañana de Córdoba, 20/11/2012). Por otro lado, recientemente el actual gobernador de la provincia ha presentado en la Legislatura provincial, a través del bloque oficialista, un proyecto de ley para reemplazar el Código de Faltas por un Código de Convivencia que, en términos generales, deja intactos sus puntos más polémicos: la figura del merodeo y la autoridad de los agentes de esta fuerza para ordenar la detención preventiva en este caso, la prescindencia de abogado defensor para la persona detenida, la obligación de identificarse ante la policía, entre otros. Para un análisis del proyecto presentado véase la nota periodística "Otro vaso vacío: la propuesta de cambios en el Código de Faltas", de Claudio Guińazú y Horacio Etchichury, publicada en Diario Comercio y justicia en $3 / 02 / 2015$ 
miseta larga, de barrios marginales, etc.- de un conflicto social que es elidido sistemáticamente a través de la apelación a falsas totalizaciones - la decencia, el escándalo, la actitud sospechosa, etc.- que ocultan la tutela de intereses particulares. Frente a esas operaciones simbólicas que construyen ideales de socialidad y prototipos de ciudadano, los actores sociales que estamos estudiando elaboran otras figuras que emergen de un trabajo de resignificación que, como dijimos anteriormente, puede rastrearse en sus modos de redefinir la espacialidad, la temporalidad y el modo de producción cultural.

De esta extensa y heterogénea red de organizaciones y colectivos que luchan por la derogación del Código de Faltas, recortaremos un "eslabón", para observar, desde una perspectiva micro, el tipo de "ecología relacional" que allí queda configurada.

$\mathrm{Si}$ nos detenemos en este nudo de la red se destaca, en primer lugar, el Colectivo de Jóvenes por Nuestros Derechos. Este colectivo nace en el año 2008, como consecuencia de la convergencia de jóvenes de distintos barrios y de distintas organizaciones sociales de la ciudad de Córdoba que exigen la plena vigencia de los derechos y las garantías constitucionales y el desmantelamiento del aparato represivo de la policía provincial. Todos los 20 de noviembre desde el año 2008, en el marco de la conmemoración de la Declaración de los Derechos de los Niños, Niñas y Adolescentes, este colectivo convoca a participar en la llamada Marcha de la Gorra, marcha que desde que se realizó por primera vez viene sumando cada año más adhesiones.

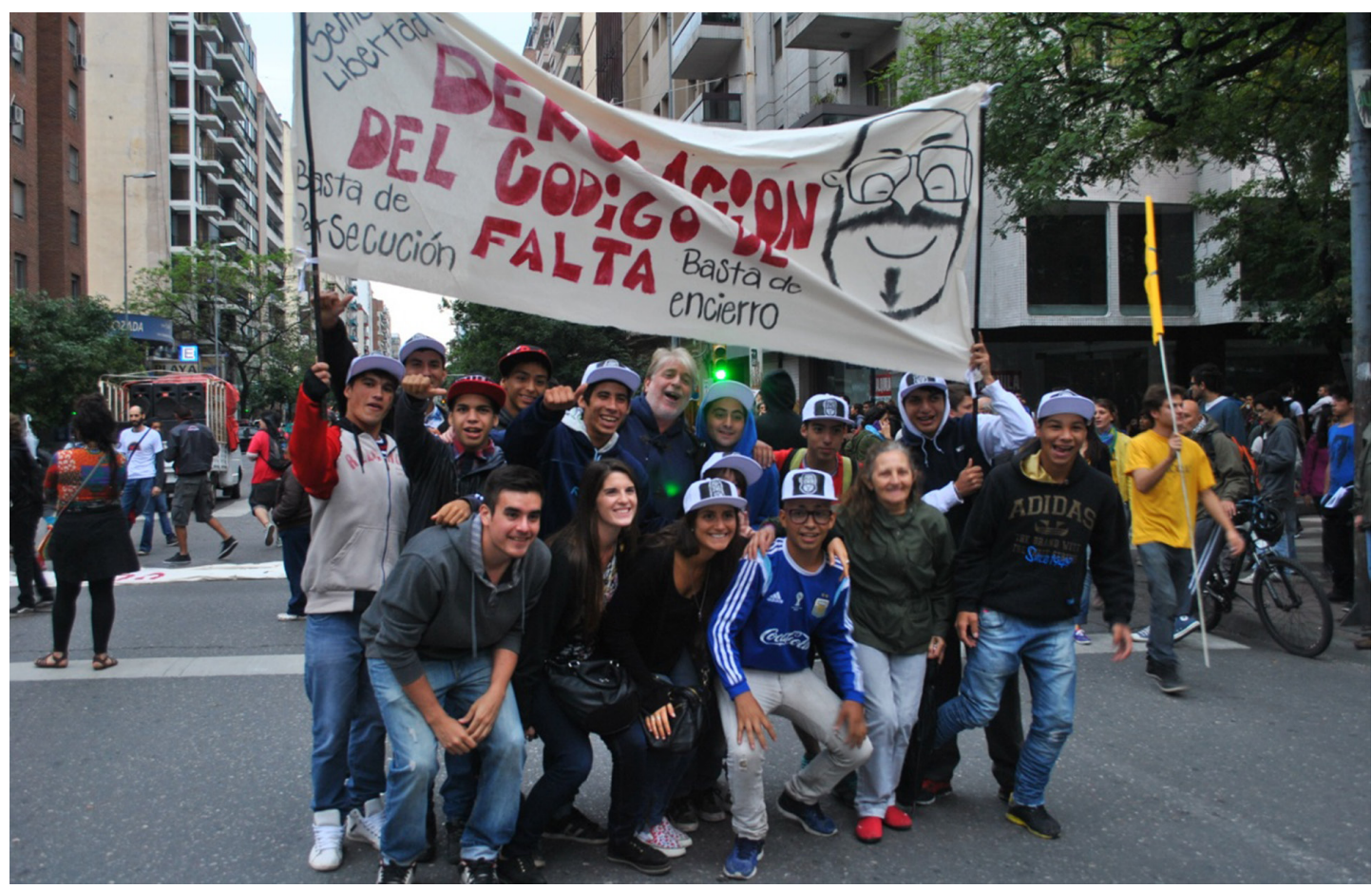

Fig. 01: Jóvenes marchando en contra del Código de Faltas en la 8va. Marcha de la Gorra, 2014. 
Ese día, la gorra, elemento de un modo de vestir propio de los jóvenes de la periferia que vienen desde los márgenes hacia el centro de la ciudad para desempeñarse en trabajos informales (limpiavidrios, vendedores ambulantes, etc.), es usada como el símbolo de una apropiación del espacio público urbano que en la vida diaria les es negado y del cual son expulsados en flagrante violación de su derecho a la ciudad. Derecho a la ciudad entendida como espacio de oportunidades y posibilidades económicas, sociales, culturales, educativas, de salud, de movilidad, de intercambio y de comunicación; pero derecho que supone, también, la posibilidad de participar democráticamente en los procesos de producción social de la ciudad como tarea colectiva orientada según criterios de bienestar común, y no como negocio librado a los intereses de un desarrollismo inmobiliario privado que goza del amparo de la política habitacional del gobierno provincial. Esa connivencia entre Estado y mercado es la que no sólo ha urbanizado la injusticia y la desigualdad, traduciéndola espacialmente al diseñar un mapa urbano que segrega a los pobres a barrios alejados del centro, de los cuales no pueden salir sin riesgo de ser detenidos por merodeo; además, ha rentabilizado inmobiliariamente los "estilos de vida", estilos que constituyen un elemento fundamental en la formación del precio de las zonas más cotizadas de la ciudad, dentro de las cuales no caben las marcas culturales de las clases populares -su "rostro" ${ }^{18}$, su música, su forma de vestir, de peinarse, de usar intensivamente el espacio público, etc.-. La presencia de la gorra en las calles que propicia la marcha -sea porque la portan los propios manifestantes, sea por su reproducción multiplicada en afiches, esténciles y grafittis- condensa toda esta disputa en torno a una matriz cultural excluyente.

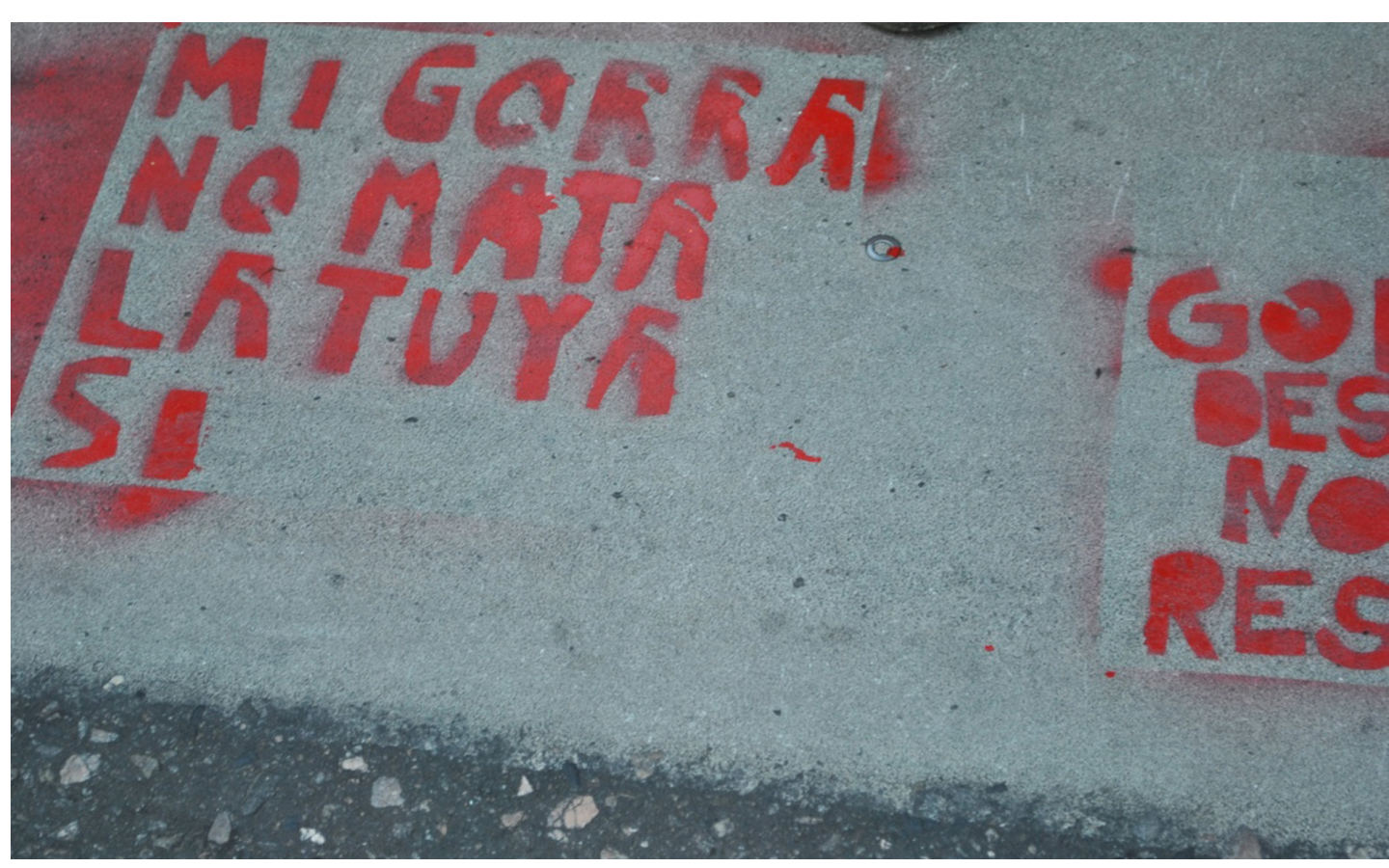

Fig. 02: Esténcil en referencia al uso de la gorra por parte de los jóvenes y por parte de los uniformados de la policía cordobesa.
18. Jugando con la frase "portación de armas", que en el discurso penal tipifica un delito, estos jóvenes denuncian que el "delito" por el cual son detenidos sistemáticamente consiste en la mera "portación de rostro". De allí la consigna "mi cara no es tu trabajo". 
19. Cf. sitio web del colectivo, http://colectivocordobes. blogspot.com.ar/p/quienessomos.html.
Por otro lado, en este eslabón que estamos examinando se encuentra también el Colectivo Cordobés por los Derechos de los Niños, Niñas y Adolescentes. Este colectivo que participa activamente en las Marchas de la Gorra y en los reclamos por la anulación del Código de Faltas, tiene como misión declarada la de "incidir en la Promoción, Ejercicio, Defensa y Exigibilidad de los Derechos de Niñas, Niños y Jóvenes a través de un Espacio Colectivo referente y legitimado construido de manera horizontal y democrática" ${ }^{19}$. Entre los varios objetivos que postula, el primero es el de dar "visibilización pública" a los niños, niñas y adolescentes, lo cual implica objetar el paradigma según el cual éstos son objeto de tutela para reconocerlos como sujetos de derecho. Se trata, por tanto, de modificar esquemas de percepción sólidamente naturalizados que corresponden a la mirada del adulto y el discurso de las instituciones. Transformar esa perspectiva requiere de la resignificación de las nociones comunes de niñez y adolescencia como condiciones "incompletas" o deficitarias; condiciones que habilitan, por otro lado, los argumentos en torno a su irresponsabilidad, su necesidad de control, su potencial peligrosidad. Visibilizar a los niños y adolescentes implica entonces cuestionar esa temporalidad que permite cercenar derechos no por lo que hacen, sino por lo que podrían hacer si no están atados al trabajo o a la escuela, sobre todo, si además de ser jóvenes son pobres. Así, una de las consignas más repetidas en las marchas -"no es merodeo, es paseo"- hace referencia directa a este cuestionamiento de los usos "lícitos" del tiempo que se les reconoce a los jóvenes de los barrios urbano marginales. Porque la figura del merodeo no sólo afecta el derecho al trabajo de todos aquellos que lo ejercen en la calle -vendedores ambulantes, cuidacoches, limpiavidrios, etc. - sino también su derecho al goce del tiempo libre.

La cuidada realización de actividades culturales no sólo durante la marcha misma (murgas, bailes, cantos, etc.) sino durante los días anteriores, tiene que ver con la reivindicación de este derecho a "pasear" entendido, en un sentido metafórico, como derecho al disfrute activo del tiempo en que el cuerpo es sacado de las constricciones que impone el tiempo laboral, sin que ello pueda ser penalizado como "actitud sospechosa”. En los últimos tres años, y a medida que la organización de la Marcha ha ido creciendo, ésta ha sido acompañada por las llamadas iJornadas Alto Embrollo!. La convocatoria para participar en estas jornadas declara que "estas, significan un espacio donde los y las jóvenes expresan libremente su(s) cultura(s), la(s) hacen pública(s), la(s) comparten con otros(as) e interpelan a la sociedad acerca 
de quiénes somos, qué hacemos, qué nos gusta y disgusta, quiénes queremos ser" ${ }^{\prime 2}$. En la última marcha de 2014, con la consigna "Vení a merodear", Alto Embrollo! fue una invitación a talleres literarios, intervenciones plásticas en la vía pública, jornadas de discusión, y un evento especial llamado Primer Flash Cultural, que fue una instancia de encuentro con colectivos fotográficos y de mediactivismo, que incluyó exposiciones y talleres de capacitación.

Este último punto se vincula estrechamente con otro problema sensible para todos los colectivos involucrados en la lucha por la derogación del Código de Falta: la cobertura comunicacional de las acciones dirigidas a exigir el cumplimiento de los derechos de jóvenes y niños, y a denunciar la sistemática represión policial. Las rutinas productivas de noticias propias de los grandes medios gráficos, televisivos y radiofónicos, organizadas sistemáticamente en torno a "fuentes autorizadas" (esto es, las instituciones policiales y gubernamentales), la ausencia de las voces y testimonios de los directamente afectados, la presentación de las disputas en torno al Código como un tema opinable y no como una ley que viola flagrantemente derechos y garantías reconocidos por la constitución nacional ${ }^{21}$ fueron algunas de las cuestiones que llevaron a autogestionar formas alternativas de cobertura comunicacional. Es así que en los últimos dos años se comenzó a construir una red colaborativa de comunicación, que apuesta a dar una cobertura democrática e igualitaria de lo que ocurre en torno a la aplicación del Código.

Luego de una primera experiencia en 2013, en el 2014 la cobertura colaborativa asumió dos formas. Por un lado, dentro del Colectivo de Jóvenes por nuestros Derechos se constituyó un área orgánica conformada por periodistas, comunicadores sociales y fotógrafos que trabajan en red con otros colectivos dedicados a la comunicación, con el fin de aunar criterios y potenciar efectos al momento de cubrir las movilizaciones sociales. Así, por ejemplo, en el marco del Primer Flash Cultural se llevó a cabo una muestra de fotografías denominado "Tu enojo: muestra de fotografía colectiva", de la que participaron los colectivos Media Ninja de Brasil, M.A.F.I.A de Buenos Aires y la producción fotográfica de la Cobertura Colaborativa Marcha de la Gorra. Esta última es una novedosa experiencia que permitió avanzar en la descentralización y democratización de la producción de información: en ocasión de la octava edición de la Marcha de la Gorra en el año 2014, el Colectivo Jóvenes por Nuestros Derechos lanzó una invitación general a "informar, mostrar, comunicar y difundir" este evento, dirigida "a todas las organizaciones sociales,
20. Cf. sitio web de la 8va. Marcha de la Gorra, http:// marchadelagorra.org/jornadasalto-embrollo/

21. En este sentido, desde el ámbito del derecho quienes rechazan al Código sostienen que "No importa si una medida es útil o no, si es inconstitucional no es aplicable". Cf. nota periodística en la página web del canal local cba24.n del 21/11/2012, http://www. cba24n.com.ar/movil/content/ codigo-de-faltas-es-insostenibleel-que-acusa-no-puede-juzgar 
22. Cf. sitio web de la 8 va. Marcha de la Gorra, http:// marchadelagorra.org/tag/ cobertura-colaborativa

23. Cf. sitio web de la agencia Mucho Palo noticias, https:// muchopalonoticias.wordpress.com

24. RANCIÈRE, Jacques, $E l$ desacuerdo: Politica y filosofía, 1996. agrupaciones juveniles o barriales, centros de estudiantes o cualquier persona que alce nuestras mismas banderas en la lucha por los derechos de lxs jóvenes" . "Si te dedicás a la fotografía, a la redacción, a filmar, a documentar audios, registráte para formar parte de nuestra Cobertura Colaborativa 2014 "22, dice la convocatoria. De esta manera fueron los propios participantes de la marcha los que asumieron en primera persona el trabajo de comunicar las acciones de resistencia a la aplicación del Código.

Por último, en este campo de observación que, por razones de espacio, hemos recortado y apartado de lo que en verdad es una larga red de relaciones entre actores que apuntan hacia un objetivo común, merece una mención aparte la cooperación de la agencia Mucho Palo Noticias. Esta agencia se define a sí misma como "Espacio de Comunicación Antirrepresivo", posicionándose como "respuesta a las indiscutibles necesidades comunicacionales de los sectores que resisten y padecen el alto nivel represivo y de control social que ejerce el Estado provincial, principalmente con la aplicación del Código de Faltas" ${ }^{23}$. Aunque el colectivo Mucho Palo nombre que juega con el uso abusivo del palo o macana por parte de la fuerza policial- realizó una cobertura exhaustiva de la última Marcha de la Gorra, el vínculo de esta agencia de comunicación antirrepresiva con los otros colectivos participantes de la Marcha va más allá de este evento anual y se asume de modo permanente, puesto que su misión es la de recoger por boca de los afectados y denunciar públicamente los numerosos casos de detenciones policiales arbitrarias, causas de gatillo fácil y torturas en cárceles y comisarías de Córdoba que no son publicados en los medios hegemónicos y que son ocultadas por la propia institución policial. Sin embargo, tanto para el caso de esta agencia como para el de la Cobertura Colaborativa, el desafío no pasa tanto por comunicar los hechos de la política, sino más bien por politizar la comunicación: esto es, por entenderla no sólo como un medio que transporta contenidos, sino fundamentalmente como un objetivo en sí mismo, por ser el escenario en el que se definen quiénes cuentan en una comunidad. La opción por la autogestión de la comunicación no sólo garantiza la participación en el circuito del acceso y distribución de noticias, sino sobre todo la participación de su producción, operación que implica, siguiendo a Jacques Ranciére ${ }^{24}$, dar parte o hacer lugar a la aparición de otros sujetos con capacidad de hablar, desencadenando así un proceso de subjetivación política y de reconfiguración de lo comunitario. 


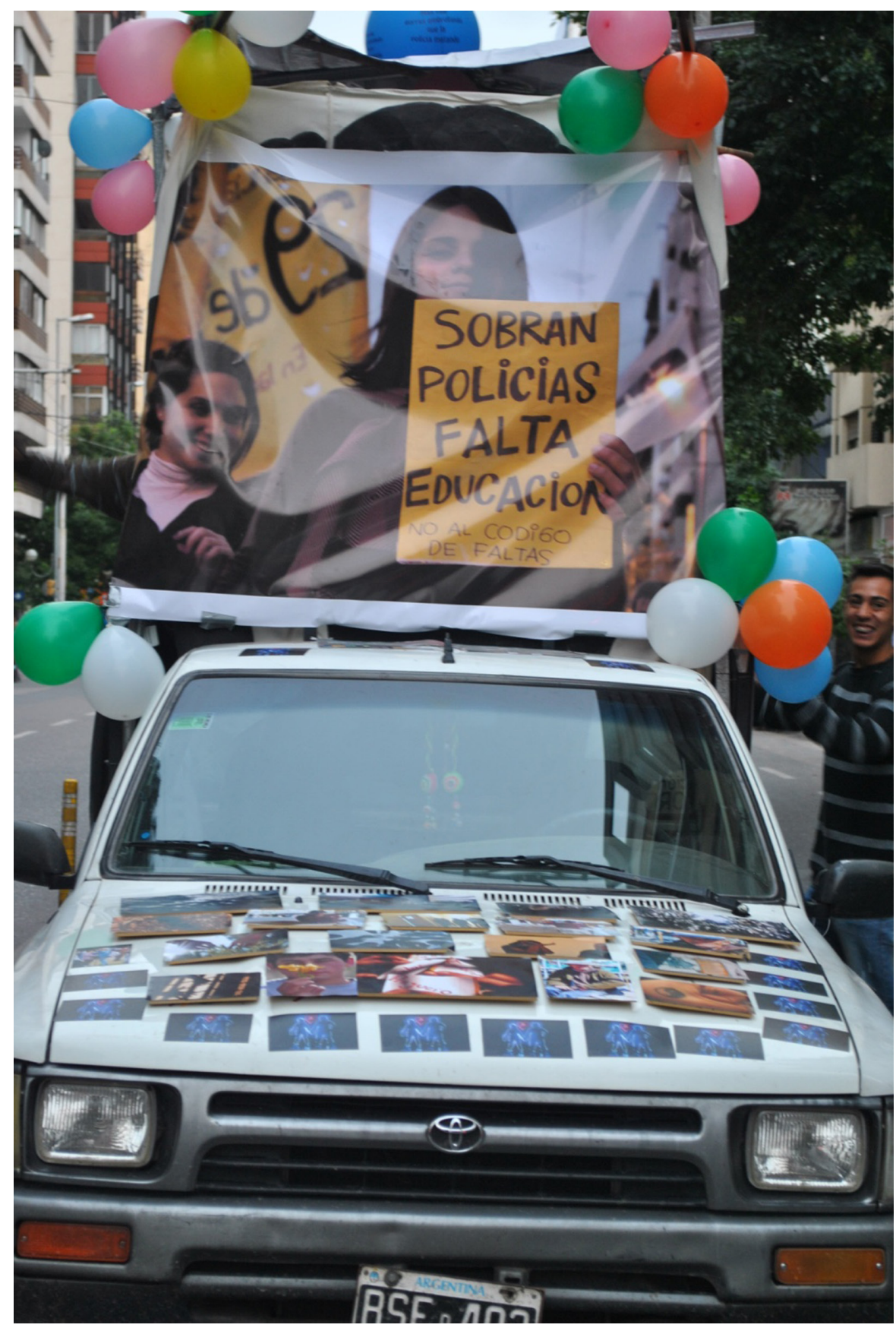

Fig. 03: 8va. Marcha de la Gorra, Córdoba, Argentina, 2014.

\section{¿Lo que "falta"? O a modo de cierre}

Son muchos más los colectivos, organizaciones, artistas y activistas involucrados en la lucha por la derogación del Código de Faltas; tantos, que sería imposible analizar en este artículo la contribución que cada uno, en particular, realiza. Sí resulta im- 
portante destacar la puesta en marcha de una serie de acciones en red a partir de una convergencia de objetivos e intereses, que, al afectar las maneras de representar la espacialidad, de concebir la temporalidad o de entender la producción de significación como hecho colectivo, resultan en estrategias de toma de la palabra y visibilización de nuevos sujetos políticos cuya emergencia misma significa una rearticulación de la comunidad. La discriminación y la exclusión que deben soportar a diario los jóvenes cordobeses de los barrios urbano marginales hunde sus raíces en una densa matriz de prejuicios que el Código recoge y vuelve operativos al ser transmutados en norma legal; se trata, como hemos visto, de una matriz para la cual todas las diferencias -de color de piel, de condición económica, de educación, de empleo comprobable- son computadas como falta, como lo que falta para ser un ciudadano decente y provechoso. A esta lectura que deduce una condición moral y cultural de las efectivas carencias estructurales, los distintos colectivos oponen, por la vía de la colaboración, una producción simbólica efectiva que da cuenta públicamente de lo que se tiene: un saber crítico acerca de sí mismos y de la sociedad en la que viven a partir del cual se evalúan las actuales formas de sociabilidad y se formulan, por la vía de la creatividad colectiva, propuestas para construir otra más justa e igualitaria. 


\section{Referencias}

EXPOSITO, Marcelo. "Arte: la imaginación política radical". Instituto europeo para políticas culturales progresivas. 2005.

Disponible en: http://eipcp.net/transversal/0106/brumaria/es. Acceso en: 13 feb. 2015.

FERNÁNDEZ VEGA, José. "Más y más variedades de lo mismo y de lo otro". Ramona. n. 34, p. 82-85, 2003.

FOUCAULT, Michel. "Las redes del poder". In: Las redes del poder. Buenos Aires: Almagesto, 1991. p. $49-72$. Disponible en: http://www.catedras.fsoc.uba.ar/heler/foucault. htm Acceso en: 22 oct. 2014.

"Post-scriptum. El sujeto y el poder". In: DREYFUS, Hubert; RABINOW, Paul. Michel Foucault: más allá del estructuralismo y la hermenéutica. Buenos Aires: Nueva Visión, 2001, p. 241-259.

GUIÑAZÚ, Claudio; ETCHICHURY, Horacio. "Otro vaso vacío: la propuesta de cambios en el Código de Faltas". Diario Comercio y justicia. 3/02/2015. Disponible en: http:// comercioyjusticia.info/blog/informacion-general/otro-vasovacio-la-propuesta-de-cambios-en-el-codigo-de-faltas/. Acceso en: 4 de febrero de 2015.

JELIN, Elizabeth. "Exclusión, memorias y luchas políticas". In: MATO, Daniel (ed.). Cultura, politica y sociedad. Perspectivas latinoamericanas. Buenos Aires: Clacso, 2005, p.219-39.

JELIN, Elizabeth; LANGLAND,Victoria (comps.). Monumentos, memoriales y marcas territoriales. Madrid: Siglo XXI, 2003.

LADDAGA, Reinaldo. Estética de la emergencia. Buenos Aires: Adriana Hidalgo, 2006.

"La producción de algo así como de vida social artificial: la práctica artística en una nueva cultura global". Ramona. n.46, p. 8-38, 2004.

"Mundos comunes. Metamorfosis de las artes del presente". Otra Parte. n. 6, p.7-13, 2005.

LASH, Scott. Crítica de la información. Buenos Aires: Amorrortu, 2005.

LECHNER, Norbert. "Los desafíos políticos del cambio cultural”. Nueva Sociedad. n.184, p. 46-65, 2003. 
LEFEBVRE, Henry. Espacio y politica. El derecho a la ciudad II. Barcelona: Península, 1976.

LONGONI, Ana. "Apuntes en medio del campo (de batalla)". In: . Mirada y contexto. Buenos Aires: Trama, 2002, p. $16-21$.

"Encrucijadas del arte activista en Argentina".

Ramona. n. 74, p. 31-43, 2007.

RANCIÈRE, Jacques. El desacuerdo: política y filosofía. Buenos Aires: Nueva Visión, 1996.

SANTOS, Boaventura de Sousa. Producir para vivir. Los caminos de la producción no capitalista. México: FCE, 2011.

WILLIAMS, Raymond. Cultura: sociología de la comunicación y del arte. Barcelona: Península, 1982.

ZIMMERMAN, Marc; OCHOA BILBAO, Luis (coords.). Giros culturales en la marea rosa de América Latina. México: LACASA / Benemérita Universidad Autónoma de Puebla, 2012. 